\title{
"Montação":
}

\section{moda na comunicação da identidade de gênero}

ISSN: 2358-0844

п. II, v. I mai. -out. 2019 р. 343-362.

Taya Carneiro ${ }^{1}$

RESUMO: Esta pesquisa objetiva entender como a moda se insere na comunicação da identidade de gênero. Adota-se uma perspectiva que olha para ambos gênero e moda como construtos histórico-culturais e políticos, estabelecendo normatividades baseadas em discursos hegemônicos. A partir de experiências de vida de travestis e mulheres transexuais, explicita-se o modo como significados simbólicos dados à vestimenta proporcionam a comunicação das identidades de gênero. A negociação de uma verdade do "sexo", e a forma como corpo e moda se relacionam e se significam se mostram centrais nesse processo de comunicação. Apresento ainda o conceito de "montação" para descrever a relação existente entre os usos da moda e a construção do corpo. Esse conceito pressupõe encarar a vestimenta como uma tecnologia de construção corporal que tem um caráter cotidiano e repetitivo.

PALAVRAS-CHAVE: moda; identidade de gênero; comunicação; travesty; transexual.

\begin{abstract}
This research aims to understand how fashion is inserted in the communication of gender identity. It adopts a perspective that looks at both gender and fashion as historical-cultural and political constructs, establishing norms based on hegemonic discourses. From the life experiences of transvestites and transsexual women, it is made explicit how the symbolic meanings given to the clothing provide the communication of gender identities. The negotiation of a truth of "sex," and the way body and fashion relate to and provide mean each other, are central to this communication process. I also present the concept of "mounting" to describe the relationship between the uses of fashion and the construction of the body. This concept presupposes seeing clothing as a body-building technology that has a daily and repetitive character.
\end{abstract}

Keywords: fashion; gender identity; communication; travesti; transsexual.

Resumen: Esta investigación objetiva entender cómo la moda se inserta en la comunicación de la identidad de género. Se adopta una perspectiva que mira a ambos género y moda como constructos histórico-culturales y políticos, estableciendo normatividades basadas en discursos hegemónicos. A partir de experiencias de vida de travestis y mujeres transexuales, se explicita el modo como significados simbólicos dados a la vestimenta proporcionan la comunicación de las identidades de género. La negociación de una verdad del "sexo", y la forma como cuerpo y moda se relacionan y se significan se muestran centrales en ese proceso de comunicación. Presento el concepto de "monto" para describir la relación existente entre los usos de la moda y la construcción del cuerpo. Este concepto presupone encarar la vestimenta como una tecnología de construcción corporal que tiene un carácter cotidiano y repetitivo.

Palabras clave: moda; identidad de género; comunicación; travesti; transexual.

${ }^{1}$ Mestranda no Programa de Pós-Graduação em Comunicação da Faculdade de Comunicação da Universidade de Brasília (PPGFAC/UnB); graduada em Comunicação Organizacional pela mesma instituição. Pesquisadora no grupo de pesquisa Cultura, Mídia e Política e no grupo Consumo e Cultura Material, ambos vinculados ao CNPq. Ativista em direitos humanos, membra da União Libertária de Travestis e Mulheres Transexuais (ULTRA). E-mail: carneiro.queiroz@yahoo.com.br 
Falamos sobre travestismo (dando-lhe este nome) problemático, o desejo de vestir roupas do sexo oposto. Geralmente não falamos sobre o forte desejo de vestir roupas do nosso próprio sexo (ou damos a isso um nome). Mas por que a maioria de nós se sentiria profundamente mal vestindo publicamente roupas do sexo oposto? O nosso forte desejo de vestir roupas do próprio sexo não sugere mistério a ser explicado? (KATZ, 1996, p. 26)

\section{Introdução}

Este artigo deriva de uma pesquisa mais ampla, direcionada a entender como travestis e mulheres transexuais usam a moda para comunicar suas identidades de gênero (CARNEIRO, 2016) feita durante primeiro e segundo semestre de 2016, no Distrito Federal. Considerando toda a abstração do fenômeno analisado, foi eleita uma metodologia que pudesse fornecer dados para entender como significados de gênero na moda, construídos em uma dimensão macro, histórica, social e cultural, se expressam em uma dimensão micro, que envolve a subjetividade e a sociabilidade. A "longa entrevista", método de pesquisa idealizado por Grant McCraken (1988), foi uma alternativa viável para analisar esse processo a partir da vivência de travestis e mulheres transexuais, pelo fato da coleta de dados ser bastante focada em categorias nativas ao grupo e por ser realizada num tempo relativamente curto.

Quanto à seleção das interlocutoras é importante ressaltar que a metodologia eleita dispensa uma grande amostra, pois busca aprofundar nos relatos para destrinchar aspectos simbólicos que são relevantes ao fenômeno. Em busca de adquirir uma maior abrangência na análise, a seleção das interlocutoras privilegiou uma grande diversidade de perspectivas que formaram diferentes aproximações com a moda. Essa diversidade foi centrada especialmente na acumulação de diferentes capitais econômicos, culturais e sociais pelas interlocutoras, considerando, sobretudo, sua raça ou cor e as especificidades geradas a partir de marcadores de diferença como classe, território e nível de escolaridade. Dessa forma, foram escolhidas quatro interlocutoras, às quais atribuí nomes fictícios para respeitar sua privacidade e destacar o caráter anônimo da pesquisa.

Claudia, que tem 23 anos, nasceu e viveu no Paraná em uma família religiosa e de classe média até recentemente, quando se mudou para Brasília para ser servidora pública. Flora, que tem 21 anos, é estudante de arte em uma universidade federal, é negra, de classe média baixa, e vive na periferia de Brasília desde o seu nascimento. Alice, de 25 anos, que também é estudante, mas de uma faculdade particular na periferia próxima ao seu local de residência. E por fim Paula, de 28 anos, que é profissional do sexo desde os 21, nasceu em Manaus, se mudou para São Paulo e depois para Brasília em decorrência de sua profissão. 


\section{Moda como comunicação da identidade de gênero}

Gênero, moda, identidade e identidade de gênero. Diferentes conhecimentos sobre esses conceitos foram construídos a partir de diferentes correntes teóricas. Em busca de operacionalizar o papel da moda na comunicação da identidade de gênero centramo-nos nas teorias que já fizeram algum tipo de relação entre esses conceitos e os fenômenos sociais que os estabelecem. Entre estes estão as teorias de gênero - ou sobre as questões relativas à mulher -, e também as teorias da moda que delimitaram como o gênero é historicamente expresso na moda.

Seguimos no caminho de Joan Scott (1995), empregando um uso do conceito de gênero que serve para "designar as relações sociais entre os sexos" (SCOTT, 1995, p. 7), referindo-se assim, às "construções sociais" sobre o papel do homem e da mulher e também às origens exclusivamente sociais da subjetividade da identidade masculina e feminina. (SCOTT, 1995, p. 5-7) Segundo a autora, “o uso do 'gênero' coloca a ênfase sobre todo um sistema de relações que pode incluir o sexo, mas que não é diretamente determinado pelo sexo nem determina diretamente a sexualidade”. (SCOTT, 199, p.7) Isso significa dizer que a empregabilidade da palavra aponta para uma tendência de rejeição ao determinismo biológico atribuído ao termo "sexo". (SCOTT, 1995, p. 3)

Ademais, o uso do termo "gênero" destaca a dimensão relacional entre os significados socioculturais e históricos que foram atribuídos aos homens (masculinidades) e às mulheres (feminilidades), ou seja, implica em assumir que não existe estudo das mulheres isolado do estudo dos homens (ibidem). Sendo assim, a discussão sobre a marcação de gênero na moda tem o olhar voltado tanto à vestimenta da mulher, quanto à do homem, evidenciando sua dinâmica interrelacional. Hollander (1996) chama atenção para essa interrelação entre o vestuário masculino e o feminino:

\footnotetext{
Mas não importa quão similar possam parecer as roupas masculinas e femininas, ou quão diferentes, as disposições de cada uma são sempre feitas com relação à outra. $\mathrm{O}$ vestuário masculino e feminino, considerado em conjunto, ilustra como as pessoas querem que a relação entre homens e mulheres seja, além de indicar a trégua em separado que cada sexo está fazendo com a moda ou costume em dado momento. Sem olhar o que os homens estão vestindo, é impossível compreender as roupas femininas, e vice-versa. (HOLLANDER, 1996, p. 17-18)
}

Ao discutirmos o gênero na "moda", reconhecemos o caráter polissêmico que esse termo moda pode adquirir, referindo-se desde a uma indústria até comportamentos, gestos, e hábitos da vida cotidiana. (CALANCA, 2008, p. 15-16) Para delimitar nosso objeto, voltamos o olhar para a indumentária. Falamos dos usos de peças que cobrem o corpo, incorporadas no ato de "se enfeitar" e 
"se vestir", tais como as roupas e os acessórios. Como mostra Suzan Kaiser, o ato de cobrir o corpo, que na cultura assume a prática cotidiana de "se vestir", corporifica a representação visual de "quem eu sou e quem eu estou me tornando". (KAISER, 2001, p. 80, tradução livre) Esse ato expressa ideias, possibilidades, ambivalências e ansiedades que seriam difíceis de expressar de maneiras verbais, lineares e conscientes. Nesse sentido, Calanca (2011) afirma que "os objetos com os quais cobrimos o corpo são as formas pelas quais os corpos entram em relação entre si e com o mundo externo". (CALANCA, 2011, p. 17)

Olhamos para a vestimenta como inserida no âmbito do fenômeno "moda" dando centralidade não somente ao seu sentido material e estético - os tecidos e o design - mas aos valores simbólicos dessa estética. Daniel Miller (2006) afirma que os significados aí presentes são capazes de materializar a cultura (MILLER, 2006), pois, como nota Braunstein (2009), o traje determina e evidencia o comportamento, marca esteticamente grupos étnicos, de classe, subculturas, e, sobretudo, a distinção entre os sexos. (BRAUNSTEIN, 2009, p. 611) Assume-se aqui, portanto, que a vestimenta, considerando seu uso como marcador social e cultural, bem como sua relação simbólica de diferenciação e indicação que envolvem o ato de "vestir-se", não possui apenas aspectos de moral privada, mas também possui um caráter de moral pública e de Direito, "situando-se já na intersecção entre a sociedade civil e o Estado". (SANTOS, 1997, p. 147) Como Santos (1997. p.147) argumenta, a moda diz respeito "à decência, aos bons costumes, às convenções hegemônicas (o que convém e é conveniente), à discrição, às boas maneiras inerentes à vida civil”. (SANTOS, 1997, p. 147)

Seguimos nessa direção, dando relevância à dimensão simbólica da estética da moda, considerando sua capacidade de materializar a cultura (MILLER, 2006) e marcar no corpo significados sociais de diferença (como classe, status, idade, afiliações à subculturas, e, sobretudo, gênero) que, na ausência de tais objetos, não seriam visíveis ou significantes. (ENTWISTLE; WILSON, 2001, p. 4) Destacando, ainda, o caráter histórico da moda, que remete à emergência da sociedade moderna na Europa e as diversas mudanças socioculturais, históricas e políticas que ocorreram na vida social europeia e foram provocadas pelos valores da modernidade. (ZAMBRINI, 2010, p. 132) Estamos, pois, tratando de um fenômeno moderno que parte da Europa e é trazido ao Brasil por meio da colonização. (SANTOS, 1997) Com sua origem estimada no período do Renascimento, a moda é relacionada à ascensão dos hábitos da burguesia. (SVENDSEN, 2010)

Zambrini (2010) localiza o desenvolvimento de uma distinção mais nítida dos usos da moda de acordo com o sexo na origem do capitalismo industrial. Já que do Renascimento até meados do 
século XIX, ambos homens e mulheres burgueses vestiam-se de maneira extravagante e lúdica, competindo com os nobres dessa forma pela manifestação de poder através das roupas. (ZAMBRINI, 2010, p. 139) A partir do conjunto de revoluções burguesas que ocorreram na Europa na metade do século XIX se consolida uma maior definição de vestuário masculino, privilegiando a uniformidade e a sobriedade advindas dos modelos da revolução francesa. (ALBERONI, 1982, p.50)

Esses valores se disseminam no vestuário masculino pela Europa e reduzem as vestimentas "não-uniformes" a "objetos carnavalescos ou folclóricos ou a indicadores de marginalidade e desvio social". (SANTOS, 1997) Os homens deixam as formas claras, alegres e elaboradas, mudando para vestimentas que conotavam retitude, elegência, formalismo, limpeza e distinção social, enquanto a estética da beleza e da sensualidade foram relegadas às mulheres. (FLUGEL, 1966, p. 100; ZAMBRINI, 2010) Assim, os padrões de vestuário femininos e masculinos se projetam em valores opostos. (MELLO, 2007)

Essa vestimenta, segundo Gilda de Mello e Souza (1987), acentuava o antagonismo entre homens e mulheres, gerando, inclusive, representações imagéticas de formatos corporais diferentes. Segundo ela, "a indumentária masculina evoluiu na sua trajetória de oblongo em pé, sólido dos ombros aos tornozelos, ao segmento de uma estrutura assemelhando-se no desenho a um H. A feminina tomou como símbolo básico de sua construção um X”. (SOUZA, 1987, p. 58) Além do estimulo à formulação de um corpo em formato de $\mathrm{X}$, a indumentária feminina foi ligada ao uso de objetos complementares à vestimenta, tais como leques, luvas, xales, bolsas, brincos, etc. (ZAMBRINI, 2010) A partir desse contexto, Zambrini (2010) defende que a indumentária passou a simbolizar a naturalização das identidades sexuais/e ou de gênero masculina em contraponto à feminina.

Os significados de gênero na moda impregnaram imaginários sociais e influenciaram a naturalização das diferenças sexuais, chegando a possibilitar uma inteligibilidade dos sexos em corpos a partir da indumentária. (ZAMBRINI, 2010) As identidades de gênero emergem paradoxalmente dessa empreitada moderna de naturalização das diferenças "sexuais" que fixa uma noção de dois sexos completamente distintos e oposicionais. (LAQUEUR, 2001) Pois ao assumir uma "natureza" do sexo, projetou-se uma psique também oposicional aos sexos.

Como Leite Junior (2011) aponta, esse cenário foi propício a uma compreensão de que o sexo corporal, dado como biológico, também provocava um sexo da mente, emergente a partir da separação interno-externo, do Romantismo do século XIX e a ascensão da mentalidade burguesa. Origina-se daí o hermafrodita psíquico, precursor do homossexual e do transexual. (LEITE JUNIOR, 2011) Anterior 
a esse período, imperava no ocidente o antigo discurso médico-filosófico e judaico-cristão, no qual a distinção entre homens e mulheres é entendida como gradações de um mesmo ser. Ou seja, até o século XVIII, estava em vigor o entendimento de que todo corpo compartimentaria os dois sexos, mas que o desenvolvimento explicitaria ou o masculino ou o feminino. (LEITE JUNIOR, 2011)

Dessa forma, as identidades de gênero pressupõem, de forma radical, que a identificação com o gênero não é determinada pelo sexo, mas sim por uma relação subjetiva com os produtos do gênero - o "universo" de significados masculinos ou femininos. A partir dessa concepção, travestis e mulheres transexuais brasileiras foram classificadas no final do século XX como identidades de gênero (CARRARA; CARVALHO, 2013), já que estas, mesmo tendo os órgãos sexuais que na concepção ocidental moderna são entendidos como masculinos, não se identificam como homens, mas sim como mulheres, ou travestis.

Ainda que falemos de identidades de gênero, nos afastamos da noção moderna de identidade, e o que Rago (1998) chama de "ilusão da interioridade e da essência" (ibidem, p. 93), prevendo um "núcleo interior" do sujeito, centrado e unificado, preservador de sua essência mesmo com o desenvolvimento. (HALL, 2006) Uma noção que promove um sujeito sociológico dotado de um “eu real" que é formado e modificado a partir do dialogo com um Outro mediador de valores, sentidos e símbolos, ou seja, da cultura. Pois, como Foucault (1997) defende, essa busca por uma essência e uniformização das identidades mobiliza uma vigilância de condutas dentro dos grupos e suscita o sentimento de inadequação e não-pertencimento, o que impede a real subversão. (FOUCAULT, 1997)

É de se considerar ainda o contexto contemporâneo de mudanças estruturais e institucionais, no qual as identidades fixas e essencialistas estão se fragmentando, comungando não em uma, mas diversas identidades, que algumas vezes se contradizem ou podem ser não-resolvidas. (HALL, 2006, p. 10-13) Segundo Stuart Hall, "o próprio processo de identificação, através do qual nos projetamos em nossas identidades culturais, tornou-se mais provisório, variável e problemático". (HALL, 2006, p. 12) Diversos autores já sinalizam que esse processo é visível na constituição das identidades travesti e mulher transexual, marcadas por constantes tentativas de definições essencialistas que nunca são entendidas como um consenso pelo movimento social. (NOGUEIRA; LEÓN, 2012)

Assim, o paradigma da fragmentação e questionamento da noção unificada e natural de identidade se transporta para a identidade de gênero. Pois enquanto os discursos médicos-biológicos e algumas teorias de gênero elevam a noção de que sexo é dado pela natureza ao patamar de "verdade ontológica", argumenta-se que a identidade de gênero não é contínua, e sim busca seguir uma 
coerência segundo da citada verdade. (BUTLER, 2015) Lauretis (1987) defende que uma subjetividade marcada pelo gênero é fortemente impelida a se dizer inteira, como uma mulher ou homem completos, de acordo com uma representação de gênero vigente. (LAURETIS, 1987)

Segundo Butler (2015), essa regulação em relação ao gênero parte dos discursos dominantes como o biomédico e o jurídico e de ideais normativos que atuam por meio da heterossexualidade compulsória. Exigindo aí uma coerência entre sexo, gênero, prática sexual e desejo. Essa regulação não se limita ao gênero, e inclui também o estabelecimento de padrões culturais - como a moda - que tornam as pessoas inteligíveis quanto ao seu gênero. (BUTLER, 2015, p. 37-56) Inspirada pela premissa pósestruturalista da fragmentação do sujeito, a autora argumenta que não existe uma continuidade na identidade, e nem tampouco existe uma identidade anterior à identidade de gênero. Segundo ela, as “identidades de gênero” têm exatamente o papel de produzir uma falsa noção de estabilidade. Ou seja, identidade não é um gênero, mas sim o efeito de atos performáticos repetitivos, que se coerentes com os padrões de inteligibilidade, produzem pessoas inteligíveis quanto ao seu gênero. Butler então defende que a identidade de gênero é performaticamente constituída. (BUTLER, 2015, p. 42-56)

É na performatividade que se encontra a importância da indumentária para o gênero na teoria de Butler, exatamente porque esta constitui um dos padrões de comportamento reconhecíveis na marcação de gênero nos corpos. Esse reconhecimento, ou nas palavras de Butler, inteligibilidade, é mediado por códigos culturais que se organizam em torno de uma "matriz de inteligibilidade de gênero", regulada pelos discursos de poder. (BUTLER, 2015) Uma elaboração semelhante à de Tereza de Lauretis (1987) que situa esses códigos na "representação" do gênero.

A ideia de Lauretis, entretanto, não acarreta num entendimento de que o gênero não tem implicações concretas ou reais, sociais ou subjetivas, mas que essa representação é sua construção. Pois a representação, como Jodelet (2002) define a partir dos estudos de Moscovici, é "uma forma de conhecimento socialmente elaborado e compartilhado, com um objetivo prático, e que contribui para a construção de uma realidade comum a um conjunto social”. (JODELET, 2002, p. 22) Essa representação se origina em um sujeito (individual ou coletivo), se refere a um objeto (é a representação de alguém ou algo) e tem um conteúdo (um discurso com expressões, imagens, idéias e valores). (JODELET, 2002, p. 22) Ou seja, o gênero como uma representação perpassa imaginários e memórias sociais e cria uma realidade composta por significados e sentidos inteligíveis, essenciais à comunicação.

Lauretis (1987), ao afirmar que o gênero é uma representação, não o encara apenas como um efeito da representação, "mas também o seu excesso, aquilo que permanece fora do discurso como 
um trauma em potencial que, se/quando não contido, pode romper ou desestabilizar qualquer representação". (Lauretis, 1987, p. 4) Isso ajuda a compreender o lugar das identidades travesti e mulher transexual como uma produção simbólica que ocorreu nas margens, ou fora do discurso de gênero hegemônico. Aquele discurso heteronormativo, que como Butler (2015) argumenta, exige a coerência heterossexual, e sobretudo, cisnormativa. Ou seja, essas identidades foram produzidas pelos sistemas de saber e poder no exterior dos territórios de inteligibilidade.

A partir da normatividade discursiva e representativa que delimita os significados de "travesti" e "mulher transexual" podemos começar a delinear os potenciais comunicativos da moda em relação às identidades de gênero. Pois, como explicita Umberto Eco (1982, p. 15), o valor comunicacional da moda está baseado em códigos e convenções bem estruturados e muitas vezes intocáveis, regulados por meio de incentivos ou sanções. A moda, de forma bem semelhante ao gênero (BUTLER, 2015; LAURETIS, 1987), manifesta “padrões, limites, imposições tácitas de ordens diversas, estabelecendo projeções típicas de comportamento para todas as categorias de indivíduos, fixando um conjunto de significações e valores de um modo sistemático”. (SANTOS, 1997, p. 147-148)

A moda cria o que Barthes (1979) considera como um sistema relativamente fechado, semanticamente perfeito e amplamente naturalizado pelas pessoas. É através desse sistema de normas que o vestuário "fala". (ECO, 1982, p. 15) Assim, a identidade de gênero comunicada pela moda utiliza-se da naturalização da binariedade de gêneros, mais especificamente das práticas culturais que Gilberto Freire (1987) classificou como "modos de homem" e "modas de mulher", que descrevem respectivamente o jeito, artes e comedimentos próprios de homens bem educados e também a imagem da feminilidade. (FREIRE, 1987) Dessa forma, como aponta Santos (1997), "ao fixar normas e padrões de vestuário para cada um dos sexos, não se permitiam mudanças, ou mesmo inversões de indumentária. Essa era a própria semantização do corpo" (SANTOS, 1997, p. 148), ou seja, a normatividade da moda que dá significado ao corpo.

Quanto mais normativo é o contexto histórico e social em relação ao vestuário e à indumentária enquanto marcadores visuais de diferenças, maior será o potencial da vestimenta de comunicar uma identidade social. Isso é facilmente perceptível quando analisamos os usos da indumentária em períodos aristocráticos, anteriores à modernidade e à própria moda como concebemos hoje. Um período que se caracteriza pela fixidez nos papéis sociais, no qual a indumentária, normatizada pelas Leis Suntuárias, definia as identidades sociais dos sujeitos de acordo com suas atividades e posição na escala social. (ZAMBRINI, 2010, p. 134) Os trajes, neste contexto, 
comunicavam a função social em consonância com a atividade desempenhada: guerreiro, campesino, servo, realeza ou cortesãos. (ZAMBRINI, 2010, p. 134)

Esse processo também é visível no Brasil, no qual a normatização dos usos da vestimenta se deu por meio de intervenções coloniais, com vistas a normatizar as vestimentas das diferentes culturas não ocidentais que viviam naquele território. Antes do século XIX, o governo português regulava a vestimenta na colônia por meio de legislações que eram operadas através de cartas régias enviadas ao governador geral e a governadores de capitanias brasileiras, dizendo respeito, por exemplo, dos trajes das mulheres escravizadas (LARA, 1997), além de estipular o que era adequado como uma vestimenta de mulher e de homem, baseando-se na tradição judaico-cristã. (MOTT, 1988)

Entretanto, ainda que hoje a legislação brasileira não disponha de leis a respeito da vestimenta como as que existiam no período colonial brasileiro e no período medieval na Europa, a cultura fica a cargo dessa normatização, operando uma vigilância constante sobre os corpos. No caso específico do gênero, a cultura estabelece os códigos pelos quais a indumentária é entendida e chega a definir os corpos. Tais códigos, organizados na representação e na matriz de inteligibilidade de gênero, atuam como mediadores da comunicação da identidade de gênero. Pois dizer que um código, um significado, é inteligível, também é dizer que ele é comunicável, e se ele é comunicável, é mediado por representações reguladas por sistemas de leis tais como o gênero e a moda.

Assim, a moda, como instrumento de comunicação da identidade de gênero, é mediada por um sistema de códigos normatizados e regulados por uma série de discursos hegemônicos. As instituições sociais entram nesse processo como uma tecnologia que vigia e pune, nos termos foucaultianos, aqueles que fazem uso "incorreto" desse instrumento de comunicação da identidade. Ao mesmo tempo, as sobras discursivas no uso da moda adquirem um poder simbólico extremamente potente, capaz, inclusive, de desafiar e transgredir concepções hegemônicas tais como as científicas. Para a moda como comunicação de uma identidade de gênero não-normativa, "o que é socialmente periférico se torna simbolicamente central". (BABCOCK, 1978, p. 32) Por isso a vestimenta tem tido um papel central na afirmação e comunicação de identidades sexuais não-heterossexuais e nãocisgênero por meio do uso das "sobras discursivas" da moda. Ruth Holliday percebeu esse potencial analisando a vestimenta de pessoas queer nos Estados Unidos, e destaca o papel comunicativo da moda na produção dessas identidades sexuais e de gênero. (HOLLIDAY, 2001)

Para concluir operacionalizando a comunicação da identidade de gênero pela moda, retomamos o conceito de performatividade de gênero de Butler - os padrões culturais de 
comportamento que tornam um corpo inteligível quanto ao seu gênero - e identificamos essa comunicação como feita por meio da significação dos objetos de indumentária pela representação e pela matriz de inteligibilidade de gênero, ou seja, a moda se torna um padrão cultural tal que tem o potencial de tornar uma identidade de gênero inteligível e portanto, comunicável.

\section{Fronteiras e limites comunicativos do corpo e da indumentária}

A partir das entrevistas realizadas, algumas relações entre a vestimenta e a construção do corpo foram consoantes à percebida no processo de aprofundamento do binarismo de gênero na moda ocorrido no inicio da modernidade. A mais evidente foi a tentativa de construção de um corpo em formato de X, semelhante à forma buscada por mulheres do século XIX, como observa Gilda de Mello e Souza (1987). Todas as interlocutoras evidenciaram que suas peças preferidas eram as que promoviam esse formato. Claudia diz que a intenção de ter tal corpo é compartilhada tanto por mulheres cisgênero, quanto por mulheres transgênero, argumentando que ambas teriam essa vontade fomentada pela moda. Claudia questiona a ideia de que a disforia de gênero seja inerente à transexualidade, baseando-se no fato de que sempre tenta esconder os ombros por considerá-los masculinos, mas que observa processos parecidos que ocorrem também com mulheres cisgênero.

Eu começo a pensar até que ponto é disforia, porque é disforia, mas as mulheres cis têm a mesma coisa. É uma disforia do gênero feminino, não é uma disforia do ser trans. É uma disforia do quão não feminina você está. Porque a mulher cis tem muito disso também. 'Ai, eu preciso emagrecer por eu tô parecendo um bujãozinho. 'É sempre uma coisa no masculino assim, o que tá dando referência ao masculino é Deus me livre, eu preciso fugir disso, sabe? (CLAUDIA, entrevista concedida em 29/02/2016)

No depoimento de Claudia fica evidente que o formato de $\mathrm{X}$ ainda é associado à imagem de um corpo feminino ideal. $\mathrm{O}$ afastamento desse formato seria caracterizado por adjetivos geralmente associados à masculinidade, como o termo "bruto" e o termo "bujãozinho" destacados no texto. O segundo indica ainda que o formato de $\mathrm{X}$ só é plenamente alcançado por corpos magros, mobilizando a valorização da magreza para o alcance da feminilidade. Em busca de alcançar esse ideal de corpo feminino, Claudia encontra na vestimenta a "correção" para a ausência de "curvas" no seu corpo. (CLAUDIA, entrevista concedida em 29/02/2016)

Essa relação entre a construção do corpo e a indumentária foi evidenciada em todas as entrevistas, nas quais o corpo em formato de $\mathrm{X}$ é encarado como a representação imagética do ideal 
de corpo feminino. As peças teriam de promover esse formato para comunicar a feminilidade e, por este motivo, a preferência estava nas peças que "marcam" a cintura, pois estas atingiriam com mais eficiência as desejadas curvas femininas simbólicas. Em geral, as que cumpriam melhor essa intenção eram as saias e os vestidos. Paula mostra uma predileção por saias de cintura alta, atribuindo a elas ainda a ideia de conforto.

Adoro usar uma blusinha, uma camisetinha, colocar uma saia de cintura alta. Adoro saia de cintura alta, tenho 3. Não gosto muito de jeans, tenho poucos jeans. Então eu gosto muito de vestido, esses vestidos longos, soltos. Eu gosto muito de conforto, tem que ser confortável por causa do pinto, né. (PAULA, entrevista concedida em 28/08/2016)

Aparece ainda um outro fator que influencia na escolha da vestimenta: a ideia de conforto associada à relação entre a roupa e o órgão sexual. Em geral, mulheres transexuais e travestis que não fizeram a transgenitalização se utilizam da vestimenta para "esconder" o pênis. Essa prática, apresentada sob o termo "aquendar a neca", consiste em colocar o pênis para trás e segurá-lo com uma roupa íntima apertada, simulando uma vagina. Nesse processo, reafirma-se a lógica hegemônica de que mulheres não podem ter um pênis, e objetiva-se uma espécie de escudo protetivo contra a possibilidade de reconhecimento da transexualidade ou travestilidade, buscando uma blindagem da violência transfóbica. Em sua fala, Paula identifica as peças usadas no processo de "aquendar", demonstrando um extremo incômodo com roupas que evidenciam seu órgão sexual.

As vezes eu vou usar uma legging, eu uso duas leggings, porque se eu usar uma 'marca'o pinto. [...] Ai eu consigo usar uma legging sem marcar muito aqui na frente porque aí fica muito feio. Eu também uso uma calcinha adequada, que a gente usa, que é própria pra esses momentos. E também tem essa aqui que eu adoro usar, que é tipo um modelador. Ela não aperta e deixa (o pênis) pra baixo. Eu posso usar um vestido e vai dar um vento e não vai aparecer. Por isso eu gosto da saia de cintura alta, porque não tem que ficar usando aquela calcinha que aperta muito. Calcinha em geral aperta muito, em certas ocasiões é bom usar, mas se eu pudesse optar eu não usava. [...] (PAULA, entrevista concedida em 28/08/2016)

Esta fala revela que a escolha de vestidos e saias de cintura alta tem a ver com a "valorização das curvas", mas também permitem “aquendar a neca" de uma forma confortável, ou seja, que não cause dor e complicações físicas. Para além da ausência de dor, a ideia do conforto está associada também à uma estética. O pênis evidenciado se apresenta como uma imagem "feia", nas palavras de Paula. Essa percepção também surge na fala de Alice. 
[...] às vezes eu fico preocupada se tá aparecendo o volume, se não tá. Aí você usa uma calcinha bem mais apertada. [...] O meu órgão não me causa transtorno. O único transtorno é se tá aparecendo o volume, se não tiver aparecendo pra mim tá ótimo. [...] Não tenho a preocupação das pessoas descobrirem que eu sou trans, é porque eu não acho esteticamente bonito. (ALICE, entrevista concedida em 12/08/2016)

Alice argumenta que o uso de uma calcinha apertada para esconder o pênis não tem a ver com evitar uma falha na comunicação de uma identidade de gênero feminina, mas se trata de um aspecto puramente estético. Entretanto, quando questionei ambas Alice e Paula o porquê da "feiura", o olhar masculino heterossexual apareceu como principal definidor do que era considerado uma estética bonita ou feia. As duas interlocutoras utilizaram o exemplo da calça legging, a grande inimiga dos pênis de mulheres transexuais, para dizer que o olhar masculino se dirige direto para o local onde fica o órgão genital quando uma mulher (tanto cisgênero, quanto transgênero) faz uso desse tipo de calça. A feiura, então, estava no estranhamento deste olhar.

A partir dessa visão, me indaguei se essa feiura, uma vez que era ditada pelo olhar masculino heterossexual, não seria avessa a uma estética transexual, pois esse olhar estaria condicionado por uma concepção de gênero heteronormativa. (BUTLER, 2015) Ou seja, ainda que Alice defenda que o processo de "aquendar" seja puramente estético, ele potencialmente teria ligação com a negação de uma comunicação da identidade de gênero transexual ou travesti. Por isso, retomando a percepção de conforto relatada por Paula, a escolha das roupas também estaria ligada a evitar a visibilidade do órgão sexual.

Ademais, além de esconder o órgão sexual e minimizar a ausência de curvas, foi perceptível nas entrevistas a necessidade de esconder no rosto características percebidas como masculinas. A maquiagem se configura como a tecnologia disponível para esse fim. Essa prática é mais evidente no início da transição, quando possíveis processos como a terapia hormonal e cirurgias plásticas não modificaram o formato do rosto, ou o uso de depilações definitivas não eliminou todos os pelos de barba. Para ilustrar esse processo imageticamente, podemos imaginar um gráfico temporal no qual apresenta-se um pico de uso excessivo de maquiagem no início da transição que vai diminuindo ao longo dos processos de transformação corporal.

Para ajudar na compreensão do processo de comunicação da identidade de gênero por meio da indumentária observados nas falas, retomamos a ideia de Entwistle e Wilson (2001) de que a moda age como marcador de significados de diferença no corpo, sendo que, neste caso, os significados 
relevantes são os que se referem ao gênero. Entre as travestis e mulheres transexuais entrevistadas, ambos corpo e moda atuam em conjunto para dar materialidade a um corpo que traduz uma subjetividade de gênero. Sendo assim, reafirma-se o que Benedetti (2005) coloca ao dizer que a "verdade" da identidade travesti é dada mais no corpo que na interioridade. O estilo da aparência das interlocutoras se torna um modelo ou uma tentativa de reivindicação de verdade sobre a identidade (quem eu sou, quem eu não sou, quem eu posso me tornar). (KAISER, 2001)

Falo de "verdade" no sentido empregado por Kaiser (2001), sendo um processo de produção de conhecimento que indivíduos usam com outros para negociar um sentido de significado ou propósito. Ou seja, a verdade aqui é encarada como um processo que necessita de um julgamento coletivo para a produção do conhecimento. A partir das ações coletivas, essa verdade é estabilizada e usada como padrão para julgar realidades. (SHAPIN, 1994, p. 4) Sendo assim, seguindo a concepção de Kaiser, pressuponho que o conhecimento não pode ser constituído exclusivamente por um indivíduo. O indivíduo só pode, pelo contrário, reivindicar novos sentidos de verdade que serão socialmente negociados. (KAISER, 2001) É possível, assim, comparar a verdade ao estilo da aparência, percebendo que ambos são construções individuais que devem ser coletivamente interpretadas de forma contínua, produzindo, dessa maneira, conhecimento e moda respectivamente. (KAISER, 2001)

O uso da moda com o objetivo de comunicar uma verdade sobre a identidade de gênero seria essencialmente uma tentativa de negociação, que deve ser coletivamente julgada para estabelecer sentido e conhecimento. A moda facilita esse processo de julgamento coletivo exatamente porque, como apontam Kaiser, Nagawasa e Hutton (1991, 1995), ela se configura como um processo através do qual grupos e culturas podem negociar maneiras comuns de expressar ambivalências complexas que não podem ser facilmente expressas em palavras. (KAISER; NAGAWASA; HUTTON, 1991; 1995)

Em alguns casos nas entrevistas que realizei, as interlocutoras julgavam que transformações corporais geradas pelo uso de hormônios e pelas intervenções estéticas "definitivas" tinham mais peso que a moda na construção da "verdade" sobre a identidade de gênero. Segundo Alice, a partir dos usos dessas tecnologias, a nova verdade identitária é plenamente percebida e entendida, ao ponto de, como também perceberam Garcia (2007) e Silva (1993) com suas interlocutoras, a moda ser irrelevante, pois “as características do sexo feminino” já haviam sido alcançadas.

Na perspectiva de Alice, o uso das tecnologias de transformação corporal aproximaria ao máximo o corpo da mulher transexual do corpo da mulher cisgênero, possibilitando o entendimento de uma identidade feminina. A partir de então, a indumentária não afetaria os significados do corpo. 
Este entendimento media uma possível predileção por essas tecnologias na comunicação da identidade de gênero. Algo que se tornou evidente nos depoimentos das interlocutoras quando propus que imaginassem uma situação hipotética na qual estariam fazendo sua transição e teriam que escolher entre realizar unicamente mudanças médico-biológicas - com hormônios e cirurgias - ou unicamente mudanças na vestimenta - com acessórios e maquiagens inclusos. Claudia e Flora, por exemplo, escolheram as mudanças médico-biológicas associando-as a um conforto subjetivo.

O corpo. [...] No meu íntimo, quando eu to sozinha em casa eu tenho o costume de andar nua. Quando eu to nua aquilo, que eu to analizando o meu corpo, aquilo é pra mim. A roupa por mais que seja pra mim tá passando a mensagem pro outro. Então eu vou estar investindo muito mais em uma coisa que vai estar passando uma imagem pro outro. Por mais que eu adore roupa, agora o corpo eu sei que é pra mim. Por exemplo, quando eu usei os hormônios não foi pros outros, foi pra eu me sentir bem. (CLAUDIA, entrevista concedida em 29/02/2016)

Eu mudaria o corpo, com certeza. Porque eu acho que os outros processos de mudança estão para além do que a sociedade te lê. Tanto que já é algo que acontece agora, eu tenho as roupas mas isso nunca é a questão. Tanto que eu quase nunca compro, tirando as maquiagens. Então o meu foco está em como eu me sinto, nos meus processos. Eu focaria com certeza em mudar o corpo, faria o tratamento hormonal, porque esta é uma questão para além de como a sociedade te lê socialmente por conta da sua roupa. (FLORA, entrevista concedida em 9/03/2016)

Percebe-se que para ambas as interlocutoras, as tecnologias médico-biológicas não têm o intuito de comunicar a identidade de gênero, como tem os usos da moda. A indumentária aparece puramente como comunicação, o vestir-se assume o lugar de relação com o outro, rejeitada em detrimento de uma relação com si mesma. A moda, no entanto, teria o maior poder de estabelecer uma verdade sobre a identidade de gênero. Pode-se perceber nas falas uma noção semelhante sobre as verdades pré-estabelecidas sobre o gênero, pois as três interlocutoras entendem que os usos da moda já podem comunicar uma identidade de gênero mesmo que o corpo carnal não seja lido como feminino. Ou ainda, que a moda pode de fato mudar o entendimento do corpo, destruindo aí a fronteira existente entre os dois. É curioso, entretanto, que Claudia e Flora, mesmo tendo essa perspectiva, tenham escolhido modificar o corpo carnal para obter um conforto subjetivo, pois isso pode indicar que elas tenham introjetado a noção moderna da existência de uma "verdade do sexo", como Foucault (1988) a denomina ironicamente.

Na modernidade ocidental, essa verdade é expressa pelo discurso de que o sexo é dado pela 
natureza - sendo esta expressa no corpo carnal -, e o gênero se trata da inscrição de códigos sociais e culturais sobre esse sexo. (SCOTT, 1995) Elas poderiam, sobretudo, estar corroborando com a noção, também moderna, de que a moda é apenas uma superfície, e que a natureza de fato estaria no corpo carnal. (TSEELON, 2001) Sendo assim, as transformações do corpo carnal atuariam como uma "correção" da natureza, para que ela tenha coerência com a identidade de gênero, exatamente como prevê o que Butler (2015) chama de ordem compulsória da heterossexualidade.

Propaga-se aí a noção de que transexuais "nasceram no corpo errado". Já que a ordem compulsória heterossexual promove uma regulação dos corpos por meio de ideais normativos e discursos dominantes como o biomédico e o jurídico, exigindo da identidade de gênero uma falsa estabilidade, expressa por uma coerência entre sexo, gênero, prática sexual e desejo. (BUTLER, 2015) Um exemplo de regulação é dado pelo próprio Código Internacional de Doenças (ORGANIZAÇÃO MUNDIAL DA SAÚDE, 1993), no qual opera o discurso biomédico, patologizando as experiências de travestis e transexuais, estipulando que o "tratamento" para as pessoas diagnosticadas com o CID do transexualismo seja a hormonização e a cirurgia de transgenitalização. Só depois de passar por essas transformações terão um corpo saudável (GARCIA, 2007, p. 21) - o que, nos termos de Butler (2015), seria um corpo heteronormativo.

Bento (2006), em sua etnografia sobre o processo transexualizador, fornece um olhar privilegiado sobre o discurso biomédico, argumentando por meio da voz das suas próprias interlocutoras que as tecnologias utilizadas no processo de transexualização só servem para tornar os corpos inteligíveis aos olhos heteronormativos. A autora nomina tais práticas e códigos que agem sobre os corpos das pessoas transexuais como "dispositivos da transexualidade", que compreendem, sobretudo, os utilizados pela medicina nas cirurgias, em busca de uma adequação dos corpos disfóricos ao corpo heterossexual. (BENTO, 2006)

Holliday (2001) também tem uma percepção semelhante, mas se utiliza da metáfora do corpo como um texto social, argumentando que a motivação que leva à dolorida transgenitalização está no fato de transexuais não conseguirem ser "lidas" de acordo com sua identidade de gênero, o que provoca uma profunda insatisfação subjetiva. (HOLLIDAY, 2001, p. 227) Ou seja, para que a verdade sobre a identidade de gênero seja lida no corpo, os "dispositivos da transexualidade" (BENTO, 2006) podem ser mais úteis que o uso da vestimenta, uma vez que o caráter maleável da indumentária pode indicar um gênero que não é coerente. Seguindo essa lógica, Pâmela Leme, colaboradora de Nogueira e León (2012) em sua pesquisa com travestis profissionais do sexo de Fortaleza, Ceará, afirma que uma bicha 
só se tornará travesti caso faça uso de hormônios femininos (NOGUEIRA; LEÓN, 2012, p. 58).

A partir do que foi discutido nessa seção, tiramos uma ideia de que os usos da moda por mulheres transexuais e travestis são bastante permeados pelas práticas de "esconder" características corporais entendidas como masculinas que não puderam ser alteradas com os usos dos dispositivos da transexualidade. Entretanto, é preciso problematizar os significados da palavra “esconder", dado que esta palavra pode indicar uma verdade obliterada, que permanece por baixo de uma fantasia - de feminilidades. Algumas questões emergem a partir dessa concepção: Um aspecto do corpo só é realmente verdadeiro se for permanente? E o que quer dizer permanente? Qual é o tempo que indica que uma mudança corporal é permanente: um dia, um ano, vários anos, o resto da vida?

As respostas para estas questões podem ser inúmeras. Destaco aqui um significado possível, que acredito ser mais interessante no sentido de disputar uma nova verdade do gênero e do sexo: o de que as práticas de esconder partes do corpo consideradas masculinas com a indumentária seriam na verdade uma remodelação, encarando, assim, o corpo como sendo fluido e facilmente modificável, vendo-o como uma roupagem, nos sentidos pregados pelas interlocutoras de Silva (1993). Algo como a ideia que Joanne Entwistle e Elizabeth Wilson (2001) expressam ao afirmarem que "vestir-se é uma prática carnal envolvendo o corpo" (ENTWISTLE; WILSON, 2001, p. 4), ou seja, a moda e a vestimenta não são meramente textuais ou discursivas, mas práticas corporeificadas. (ENTWISTLE; WILSON, 2001, p. 4)

A partir dessa noção teríamos um corpo diferente de acordo com a "montagem" que fizéssemos a partir da moda. A palavra "montação", que dá nome a esta pesquisa e foi emprestada do vocabulário apreendido na sociabilidade de travestis e mulheres transexuais, dá nome a esse processo. Nomeia a comunicação da identidade de gênero que seria efetuada visualmente pela estética do corpo, com o auxilio da estética da indumentária. A montação de travestis e mulheres transexuais, a partir das vivências dessa pesquisa, seria permeada pela uso da vestimenta que promove a construção do formato do corpo em X. E seria acompanhada pela remodelação das características lidas como masculinas por meio da indumentária e dos usos das tecnologias médicas.

Os usos da moda seriam complementares às transformações corporais nesse processo, e visariam a construir e comunicar um corpo feminino, sem "falhas", uma vez que as falhas têm o potencial de comunicar o erro, aquilo que está fora da representação de uma identidade de gênero feminina, e tem força simbólica suficiente para a acusação de desvio. Esse desvio, assim como entende Becker (1973), não está inscrito no comportamento, mas sim num contexto de interação. Está associado 
a uma noção de acusação (VELHO, 2003), na qual atores sociais acusam outros de quebrarem comportamentos, normas, ou valores, desestabilizando a ordem vigente. (VELHO, 2003, p. 23) Vimos que o formato ou o volume de um pênis num corpo entendido como o de uma mulher causará o estranhamento, e pode definir o indivíduo como sendo uma travesti, ou até mesmo um homem desviante, o que pode ser potencialmente perigoso frente a extensa vigilância do gênero no ocidente.

Podemos, a partir de então, começar a delinear o lugar do vestir-se na comunicação da identidade travesti e mulher transexual como um ato repetitivo e cotidiano. Uma "corporificação" performática diária de suas subjetividades, em busca de uma expressão não verbal de suas identidades. O gênero e a moda, nessa prática, assumem o papel de principais mediadores de significados. Ainda que seja recorrente nos relatos das interlocutoras a intenção de remodelação do corpo a partir dos usos da moda e dos dispositivos da transexualidade (BENTO, 2006), não existe uma fórmula pronta que estipula qual objeto de moda ou qual transformação corporal será determinante para que uma travesti ou uma mulher transexual tome forma e comunique sua identidade de gênero. É perceptível que essas identidades se expressam visualmente por meio do corpo, cobrindo-se com objetos associados culturalmente ao gênero feminino. Mas essa expressão não é continua, nem possível de ser esquematizada de forma rígida.

\section{Considerações finais}

Esta pesquisa analisou a moda na comunicação da identidade de gênero, desde o contexto macro - cultural, histórico, político - e como este se relaciona com o micro - a sociabilidade, a subjetividade. Nesse trajeto, foi possível identificar alguns aspectos que permeiam representações de gênero, identidade, identidade de gênero, sexo, moda, e sobretudo, daquilo que representa o desvio nos usos da moda de acordo com o gênero, percebendo como essas representações de alguma forma mediavam as relações das travestis e mulheres transexuais entrevistadas com seu corpo, com sua subjetividade, com a forma como concebiam sua identidade e interagiam com grupos sociais e com a sociedade. A partir daí, o foco se voltou à maneira como essas relações se traduziam em seus usos da moda e como esses usos serviam, sobretudo, para comunicar essa gama de significados construídos nos citados contextos.

A partir das entrevistas foi possível entender qual a relação existente entre o corpo e a indumentária na comunicação da identidade de gênero. Essa relação construiu uma fronteira que se mostrou fluida em muitos casos, tendo o corpo adquirido significados usualmente atribuídos ao 
vestuário e à indumentária e vice-versa. Estes, em conjunto com a maquiagem, se constituem como ferramentas de comunicação da identidade de gênero, marcando os usos da moda como uma prática feita "para o outro" e não para si. As tecnologias de transformação médico-biológicas do corpo, por sua vez, se tornam uma prática para si, relacionada a um conforto subjetivo. Apresento ainda o conceito de “montação" para descrever a relação existente entre os usos da moda e das tecnologias biomédicas para a comunicação da identidade de gênero. Esse conceito pressupõe também encarar a vestimenta como uma tecnologia de transformação corporal que tem um caráter mais cotidiano e repetitivo.

A desconstrução dos discursos também aparece nessa pesquisa como uma ferramenta de combate à naturalização da marcação da diferença que muitas vezes atua a favor da hierarquização de grupos e da discriminação. Essa desconstrução prevê uma extensa análise da construção social, cultural e histórica do discurso e das representações que significa. Nesse sentido essa pesquisa não se propõe a encerrar o mapeamento de significados que permeiam a representação dos usos da moda por travestis e mulheres transexuais. Mas evidencia que ainda são extremamente escassos os estudos sobre a historia da construção dessas identidades no Brasil e das práticas que são envolvidas nessa construção.

Algumas indagações ainda pairam dessa pesquisa, como a relação da indústria da moda com os usos da moda por travestis e mulher transexuais. Como essa indústria, incluindo aí a publicidade e o jornalismo, que atuam na produção simbólica da moda, impactam as motivações para os usos, ou seja, mobilizam o consumo de moda. Considerando ainda a afirmação da versão americana da revista Vogue de que o movimento trans se tornou mainstream em 2015 por meio da moda (THE..., 2015), indicando que a relação entre a moda e pessoas trans já está se estreitando na indústria. É preciso ponderar ainda que considerar estratégias políticas como tendências pode ser perigoso, pois pode atribuir um caráter efêmero e passageiro às demandas sociais, impedindo que sejam realmente concretizadas. 


\section{Referências}

ALBERONI, F. "Observações sociológicas sobre o vestuário masculino". In: ECO, H.; SIGURTA, R.; LIVOLSI, M. et al. Psicologia do vestir. 2. ed. Lisboa: Assírio e Alvim, 1982. p. 51-63.

BABCOCK, B. The Reversible World: symbolic inversion in art and society. Ithaca: Cornell University Press, 1978.

BARTHES, R. Sistema da Moda. São Paulo: EdUSP, 1979.

BENEDETTI, M. R. Toda feita: o corpo e o gênero das travestis. Rio de Janeiro: Garamond, 2004.

BENTO, B. A reinvenção do corpo: sexualidade e gênero na experiência transexual. Rio de Janeiro: Garamond, 2006.

BUTLER, J. Problemas de gênero: feminismo e subversão da identidade. 8. ed. Rio de Janeiro: Civilização Brasileira, 2015.

BRAUNSTEIN, P. Abordagens da intimidade nos séculos XIV e XV. In: ARIÉS, P.; DUBY, G. História da Vida Privada 2: da Europa Feudal à Renascença. São Paulo: Companhia das Letras, 2009. p. 552-646.

CALANCA, D. História Social da Moda. São Paulo: Ed. Senac, 2008.

CARVALHO, M.; CARRARA, S. Em direção a um futuro trans? Contribuição para a história do movimento de travestis e transexuais no Brasil. Sexualidad, Salud y Sociedad Revista Latinoamericana, Rio de Janeiro, n. 14, p. 319-351, 2013.

ECO, U. O hábito fala pelo monge. In: ECO, H.; SIGURTA, R.; LIVOLSI, M. et al. Psicologia do vestir. 2. ed. Lisboa: Assírio e Alvim, 1982. p. 7-20.

ENTWISTLE, J.; WILSON, E. B. Body Dressing. Nova York: Berg, 2001.

FLÜGEL, J. C. A Psicologia das roupas. São Paulo: Mestre Jou, 1966.

FOUCAULT, M. Sex, power and the politics of identity. In: RABINOW, P. (org.).

FOUCAULT, M. Ethics, Subjectivity and Truth: the essencial works of Michel Foucault, 1954 - 1984. New York: The New Press, 1997. v. 1, p. $163-173$.

FOUCAULT, M. História da Sexualidade I: a vontade de saber. Rio de Janeiro: Graal, 1988.

FREIRE, G. Modos de homem e modas de mulher. Rio de Janeiro: Record, 1987.

GARCIA, M. R. V. Dragões: gênero, corpo, trabalho e violência na formação da identidade entre travestis de baixa renda. 2007. Tese (Doutorado em Psicologia Social) - Instituto de Psicologia, Universidade de São Paulo, São Paulo, 2007.

HALL, S. A identidade Cultural na Pós-Modernidade. 11. ed. Rio de Janeiro: DP\&A, 2006.

HOLLANDER, A. O sexo e as roupas. Rio de Janeiro: Rocco, 1996.

HOLLIDAY, R. Fashioning the Queer Self. In: ENTWISTLE, J.; WILSON, E. B. Body Dressing. Nova York: Berg, 2001. p. 215-232.

JODELET, D. Representações sociais: um domínio em expansão. In: JODELET, D. (org.). As Representações sociais. Rio de Janeiro: EdUERJ, 2002. p. 17-44.

KAISER, S. Minding Appearances: style, truth, and subjectivity. In: ENTWISTLE, J.; WILSON, E. B. Body Dressing. Nova York: Berg, 2001. p. 79-102.

KAISER, S.; NAGASAWA, R. H.; HUTTON, S. S. Fashion, Postmodernity, and Personal Appearance: a symbolic interactionist formulation, Symbolic Interaction, California, v. 14, n. 2, p. 165-85, 1991.

KAISER, S.; NAGASAWA, R. H.; HUTTON, S. S. Construction of an SI Theory of Fashion: Part 1. Ambivalence and Change, Clothing and Textiles Research Journal, Corvallis, v. 13, n. 3, p. 172-183, 1995.

KATZ, J. N. A Invenção da Heterossexualidade. Rio de Janeiro: Ediouro, 1996.

Periódicus, Salvador, n.11, v. 1, mai-out.2019 - Revista de estudos indisciplinares em gêneros e sexualidades Publicação periódica vinculada ao Núcleo de Pesquisa NuCuS, da Universidade Federal da Bahia - UFBA ISSN: 2358-0844 - Endereço: http://www.portalseer.ufba.br/index.php/revistaperiodicus 
LAQUEUR, T. Inventando o sexo: corpo e gênero dos gregos à freud. Rio de Janeiro: RELUME-DUMARÁ, 2001.

LARA, S. H. Sob o signo da cor: trajes femininos e relações raciais nas cidades do Salvador e do Rio de Janeiro, CA. 1750-1815. Campinas: Ed.UNICAMP, 1997. Mimeografado.

LAURETIS, T. The technology of gender, in: LAURETIS, T. Technologies of gender. Bloomington: Indiana University Press, 1987. p. 1-30.

LEITE JUNIOR, J. Nossos corpos também mudam: a invenção das categorias "travesti" e "transexual" no discurso científico. São Paulo: Annablume, 2011.

MCCRACKEN, G. The Long Interview. Thousand Oaks: Sage, 1988.

MELLO, J. L. D. Onde vocé comprou esta roupa tem para homem? : a construção de masculinidades nos mercados alternativos de moda. Rio de Janeiro: Record, 2007.

MILLER, D. Introduction. In: KÜCHLER, S.; MILLER, D. Clothing as Material Culture. 2. ed. Oxford: Berg, 2006. p. 1-20.

MOTT, L. Escravidão, Homossexualidade e Demonologia. São Paulo: Ícone Editora, 1988.

NOGUEIRA, F. J. S.; LEÓN, A. G. "Trabalhadas no feminino": um estudo sobre corpo, desejo e prostituição travesti em Fortaleza/CE. Revista Latinoamericana de Estudios sobre Cuerpos, Emociones y Sociedad, Córdoba, v. 4, n. 8, p. 55-67, 2012.

ORGANIZAÇÃO MUNDIAL DA SAÚDE. Décima Revisão da Classificação Internacional de Doenças e de Problemas Relacionados à Saúde (CID 10). Geneva: Organização Mundial da Saúde, 1993. Edição Eletrônica.

QUEIROZ, T. C. S. Montação: os usos da moda na comunicação da identidade de gênero de travestis e mulheres transexuais. 2016. Trabalho de Conclusão de Curso (Bacharelado em Comunicação Social) - Faculdade de Comunicação, Universidade de Brasília, Brasília, DF, 2016.

RAGO, M. Descobrindo historicamente o gênero. Cadernos Pagu, Campinas, n. 11, p. 8998, 1998.

REITER, R. R. (org.). Toward an Anthropology of Women. Monthly Review Press, Nova York, p. $157-210,1975$.

SANTOS, J. T. Incorrigíveis, afeminados, desenfreiados: indumentária e travestismo na Bahia do século XIX. São Paulo: Revista de Antropologia, São Paulo, v. 40, n. 2, p. 145-182, 1997.

SCOTT, J. Gênero: uma categoria útil para a análise histórica. Recife: SOS-Corpo, 1995.

SHAPIN, S. A Social History of Truth. Chicago: The University of Chicago Press, 1994.

SILVA, H. Travesti: a invenção do feminino. Rio de Janeiro: RELUME- DUMARÁ: ISER, 1993.

SOUZA, G. M. O Espírito das roupas: a moda no século dezenove. São Paulo: Companhia das Letras, 1987.

SVENDSEN, L. Moda uma filosofia. Rio de Janeiro: Zahar, 2010.

TSEËLON, E. From Fashion to Masquerade: towards na ungendered paradigm. In: ENTWISTLE, J.; WILSON, E. B. Body Dressing. Nova York: Berg, 2001. p. 103-120.

THE Year in Fashion: the trans movement went mainstream in 2015, and fashion led the way. Vogue, New York, 2015. Disponível em: http://www.vogue.com/13377904/fashionembraces-gender-blurring/. Acesso em: 10 dec. 2018.

VELHO, G. (org.). Desvio e Divergência: uma crítica da patologia social. 8 ed. Rio de Janeiro: Zahar, 2003.

ZAMBRINI, L. Modos de vestir e identidades de género: reflexiones sobre las marcas culturales en el cuerpo, Nomadías, Santiago, n. 10, p. 130-149, 2010. 